\title{
Science and Building Exhibition
}

$\mathrm{T}$ HE Building Centre at 158 Bond Street, London, W.1, is an organization formed by architects and others associated with the industry, and supported by official bodies for the benefit of all engaged or interested in building. Its most prominent function. is the formation and maintenance of a permanent but continually changing exhibition of building materials and equipment, where a technical staff is available to give unbiased information regarding these. Its range of usefulness to the industry and to the general public is extended by special temporary exhibitions held from time to time and by lectures on cognate subjects. In another direction, a very important contribution to the progress of building technique is being made by the work of the several research stations engaged on one or other aspect of this many sided subject and the Department of Scientific and Industrial Research has arranged at the Centre a special Science and Building Exhibition to remain open until March 25.

In relation to timber, the Forest Products Research Laboratory has been engaged on several lines of investigation. The attack of insects is under constant inquiry involving the study of their food supplies and digestive processes. Here, emphasis is given to the fact that the lyctus beetle is the most serious cause of loss in Great Britain. In relation to fungus attack, models of properly and improperly ventilated buildings show how the progressive destruction occasioned by dry-rot can be avoided, while in another section the quantitative relation of moisture content to shrinkage of timber is demonstrated. Two other lines of inquiry relate to the wearing qualities of wood and to the best cutting angles of woodworking tools. In the former, a comparative test has been devised whereby the relative value of each sample of wood can be stated, while the improvements obtained in economy and finish resulting from the latter investigation can only be adequately appreciated by inspection of the results.

Geological data regarding sites and resources of building stones, clay pits, limestones, etc., come within the province of the Geological Survey and Museum which, manifestly, can exhibit here only a few items from the store of maps, publications and other accumulated information available at its headquarters.

The pivot of this Exhibition may be said to be work of the Building Research Station, wholly directed as it is to the interests of the industry. It exhibits are of a varied nature. Here are on view examples of tests on concretes, plasters, bituminous preparations, etc., and of the machinery devised for the testing and correct manipulation of the materials in use. Photographs are shown of the full-size tests oonducted under fire conditions at the Elstree Fire Research Station.

The insistent problem of noise and its mitigation is dealt with at the National Physical Laboratory, and several models are exhibited to show how the use of suitable materials and methods of construction can eradicate its worst effects. The conditions under which double walls and windows can be made effective, the right use of floating flooring to reduce impact noises, the elastic support of machinery and the application to walls of sound absorbent linings are demonstrated by means of models fitted with stethoscopes. On analogous lines, the work being done in connexion with illumination, wind pressures on structures and vibrations in roads and buildings is illustrated by means of diagrams and models.

In a series of photographic sequences, some aspects of the work of the Paint Research Station can be studied. A good paint requires to possess certain definite and distinct properties at different stages in its life-flow and 'brushability' during application, drying properties in the next stage, and elasticity, durability and appearance in its finished state. The photographs illustrate the tests applied at each stage and those also to which the raw materials are sub. jected. Of especial interest are those illustrating the electron diffraction camera used for ascertaining surface properties of pigments, the pattern obtained on a photographic negative and finally the actual atomic structure which can be deduced therefrom.

The Water Pollution Research Board and Chemical Research Laboratory have exhibits of fuller's earth in various conditions and of base-exchange and acidexchange resins. These have been found to possess water-softening properties and the samples illustrate several stages in the processes of preparation. Apparatus used in determining the average concentration of lead in water for cooking and drinking is shown together with specimens illustrating the rate of the action of water on lead. Another activity represented is the purification of effluents from dairies and milk-products factories.

Domestic heating comes within the programme of the Fuel Research Station, the staff of which are showing samples of several fuels and are prepared to advise on this point with due respect to the national prejudice in favour of the open fire. The measurement of conditions in the domestic chimney is shown, and it is explained that so easily are these upset that special precautions are necessary as, for example, in ascertaining the amount of air passing up the chimney it is necessary to seal the room and admit air by one aperture in which the anemometer is placed.

A steel structure model illustrating the stages in the construction of multi-story flats is exhibited by the Iron and Steel Industrial Research Council and shows a number of alternative exterior treatments. Other exhibits and models illustrate the preparation and uses of 'foamed slag' for light-weight concrete. The British Non-Ferrous Metals Research Association is represented by tests on the behaviour of galvanizing and zinc coatings in domestic hot-water systems. The glass apparatus shown is used to test materials either in replacement of the corresponding glass part or by suspending a sample in the apparatus. The B.N.F. jet test, also exhibited, is designed to determine simply and rapidly the thickness of a metal coating, and an outline is given of the more important points emanating from the Association's research on the frost-bursting of water pipes.

Further opportunities of learning of these activities will be given in a number of lectures by members of research stations during the period of the exhibition. 